\title{
EMPREENDEDORISMO EM PORTUGAL DE IMIGRANTES DE PAÍSES FORA DA UNIÃO EUROPEIA
}

\author{
S. R. PAÇO ${ }^{1}$, M. C. P. RAMOS ${ }^{2}$ \\ ${ }^{1,2}$ Universidade do Porto (UP), Faculdade de Economia (FEP) \\ suzy94paco@gmail.com ${ }^{1}$ \\ cramos@fep.up.pt ${ }^{2}$
}

Submetido 12/02/2018 - Aceito 20/03/2018

DOI: $10.15628 /$ holos.2018.6924

\section{RESUMO}

O crescimento positivo do empreendedorismo imigrante na Europa e o reconhecimento da sua capacidade de criar novos postos de trabalho aumentaram a importância atribuída a esta temática a nível internacional. No entanto, em Portugal, pela escassez e dispersão de dados, a investigação ainda é limitada, importando caracterizar o empreendedorismo imigrante neste país, através da distinção por género, idade, nacionalidade, educação e atividades, e determinar qual o seu contributo. Assim, através de entrevistas semiestruturadas, foi possível obter depoimentos de imigrantes provenientes do Brasil, China, Bangladesh, Ucrânia, Rússia e Índia. Em suma, os empreendedores entrevistados contribuem positivamente em Portugal, criando emprego e transmitindo novos conhecimentos e competências. No que respeita à sua caracterização, os resultados revelaram uma maior presença masculina, empreendedores com idade acima dos 40 anos, de nacionalidade essencialmente brasileira, com qualificações média/alta e com investimentos sobretudo nos setores do retalho e prestação de serviços. Os entrevistados evidenciaram que a burocracia e a língua do país de acolhimento são algumas das dificuldades sentidas na concretização do seu empreendimento e que o envolvimento com associações empresariais e de imigrantes é reduzido.

PALAVRAS-CHAVE: Empreendedorismo imigrante, caracterização, contributos, imigração em Portugal.

\section{ENTREPRENEURSHIP IN PORTUGAL OF IMMIGRANTS FROM COUNTRIES OUTSIDE THE EUROPEAN UNION}

\begin{abstract}
The positive growth of immigrant entrepreneurship in Europe and the recognition of its ability to generate new jobs increased the importance associated to this topic in an international level. However, in Portugal, due to the scarcity and dispersion of data, research is still strongly limited, and it is important to characterise immigrant entrepreneurship in Portugal by gender, age, nationality, education level and sector of activity, and to consequently determinate what is its contribution. Thus, using semi-structured interviews, it was possible to gather testimonies from immigrants coming from Brazil, China, Bangladesh, Ukraine, Russia and India. Overall,
\end{abstract}

the interviewed entrepreneurs make a positive contribution to Portugal, creating jobs and transmitting new knowledge and competences. In what concerns their demographic profile, results show a higher presence of male entrepreneurs above 40 years old, most of them Brazilian citizens, with medium to high education level and investing mostly in sectors such as retail and services. Interviewees pointed bureaucracy and the language of the host country as some of their difficulties in the establishment of their businesses, and that their involvement with corporate and migrant associations is low.

KEYWORDS: Immigrant entrepreneurship, characterization, contributions, immigration in Portugal. 


\section{INTRODUÇÃO}

Os imigrantes são frequentemente reconhecidos como altamente empreendedores (Fairlie \& Lofstrom, 2013). Nos finais do século XX, verificou-se um crescimento da importância atribuída ao empreendedorismo entre imigrantes e minorias étnicas, isto porque aumentaram as oportunidades nas pequenas empresas e expandiram-se os fluxos de imigração (Kloosterman \& Rath, 2010). Com efeito, desde os finais da década de 1980 que o empreendedorismo de migrantes tem aumentado significativamente na Europa, representando um tema importante nos países europeus (Baycan-Levent \& Nijkamp, 2009). Contudo, é de notar que a propensão para estes se tornarem empresários em Portugal difere entre os grupos de imigrantes e que, adicionalmente, as taxas de empreendedorismo e/ou de emprego criado pelos imigrantes variam ao longo do tempo (Oliveira, 2010). Oliveira (2005) acrescenta que ao longo dos anos os empresários imigrantes têm-se disseminado em Portugal e desenvolvido novas estratégias de inclusão económica, admitindo ainda que as características do país de acolhimento podem ter impacto nas estratégias e iniciativas empresariais dos imigrantes. Assim, revela-se pertinente realizar uma investigação sobre as várias vertentes que compõem o empreendedorismo imigrante, bem como o seu consequente contributo para o país de acolhimento, neste caso Portugal, onde os estudos existentes são ainda escassos.

Face ao exposto, a presente investigação realiza uma distinção dos empreendedores por género, idade, nacionalidade, educação e setores/atividades, tornando possível, desta forma, um maior aprofundamento do tema, que, como supracitado, tem ganho relevância na Europa. Adicionalmente, torna-se também fulcral o entendimento do contributo que o empreendedorismo imigrante tem em Portugal. Os imigrantes contribuem para uma economia quer como empregados, quer como empreendedores, criando novas empresas e negócios (Desiderio \& Salt, 2010). Os mesmos autores advogam que entre 2000 e 2010 se verificou um aumento da contribuição dos imigrantes para o crescimento da atividade empresarial e a criação de emprego nos países da Organização para a Cooperação e o Desenvolvimento Económico (OCDE). Assim, torna-se importante conhecer a sua contribuição para Portugal, quer no que respeita à criação de oportunidades de internacionalização de empresas, quer relativamente a outras potencialidades que oferecem ao país.

Para além de grande parte se focar no América do Norte, os estudos já existentes apresentam, essencialmente, generalizações para a Europa ou para a OCDE, onde Portugal surge em algumas conclusões (e.g. Desiderio \& Salt, 2010; Mestres, 2010), e os mais extensivos, que se focam apenas em Portugal, debruçam-se fundamentalmente sobre uma vertente, como o género (Malheiros \& Padilha, 2010), ou sobre as estratégias de inserção e tendências das iniciativas empresariais dos empreendedores imigrantes (e.g. Oliveira, 2005, 2008, 2010). Desta forma, o objetivo da presente investigação é, através do contributo de entrevistas aprofundadas, compreender as várias vertentes do empreendedorismo imigrante e o seu contributo em Portugal, bem como, recorrendo a uma metodologia qualitativa, e através de uma exploração aprofundada, reduzir a lacuna existente na literatura relativamente a este tópico num país de acolhimento como Portugal. 


\section{REVISÃO BIBLIOGRÁFICA}

\subsection{Empreendedorismo imigrante}

Para uma correta compreensão do empreendedorismo imigrante, importa conhecer dois conceitos-chave: «empreendedorismo» e «imigrante».

Schumpeter (1934) (cfr. Fee \& Rahman, 2014) defende que o empreendedorismo tem como essência a utilização dos recursos existentes de uma forma distinta, fazendo coisas novas com eles, independentemente de os aumentar ou não. Assim se compreende que um empreendedor é, por definição, aquele que ou introduz um novo bem, um novo método de produção, ou abre um novo mercado, ou ainda aquele que descobre uma nova fonte de abastecimento de materiais raros ou de reorganização de uma indústria (Fee \& Rahman, 2014).

Por sua vez, Ahmad e Seymour (2008) focam a definição de "empreendedorismo» no objetivo de criar valor, afirmando que empreendedores são aqueles que desenvolvem uma ação com esse objetivo, fazendo-o, tal como referido por Schumpeter (1934) (cfr. Fee \& Rahman, 2014), através da criação ou expansão de uma atividade económica ou da identificação de novos produtos, processos ou mercados.

De uma forma mais ampla, Caetano et al. (2014) consideram que, além da introdução de novos produtos e processos produtivos no mercado, também defendido anteriormente, 0 empreendedorismo consiste, entre outras coisas, no desenvolvimento de uma organização, na abordagem de mercados externos e no financiamento do crescimento do novo negócio através de capitais externos.

Em suma, existe uma concordância entre os autores relativamente ao facto de o empreendedorismo envolver a criação, seja de um produto, método/processo produtivo, seja de um mercado.

No que respeita ao conceito de «imigrante», Sasse e Thielemann (2005) e Oliveira (2010) afirmam que este corresponde ao indivíduo que migrou para um país diferente do território onde nasceu e onde passa a residir/residiu pelo menos durante um ano. Perruchoud e Redpath-Cross (2011) identificam, num glossário da Organization International for Migration (OIM), o imigrante como aquele que inicia a imigração, sendo este um processo através do qual os «não nacionais» se movem para outro país com a finalidade de aí se estabelecerem.

Importa notar que existem dois tipos de imigrante: o permanente e o temporário. Segundo o Instituto Nacional de Estatística de Portugal (INE, 2003), o imigrante permanente é o indivíduo que, tendo residido no estrangeiro de forma ininterrupta por um período igual ou superior a um ano, tenciona permanecer no país onde entrou, durante pelo menos um ano. $O$ imigrante temporário, segundo a mesma instituição, distingue-se do imigrante permanente, uma vez que visa permanecer no país onde entrou por menos de um ano, tendo residido no estrangeiro de forma contínua pelo menos durante um ano.

Face ao exposto, Desiderio e Mestres-Domènech (2011) definem o empreendedorismo imigrante como a atividade empreendedora desenvolvida por empresários nascidos num outro país que não o da sua atual residência. 


\subsection{Motivos para os imigrantes empreenderem}

O empreendedorismo surge como forma de os imigrantes se inserirem num país de acolhimento e na sua economia (Kloosterman \& Rath, 2010). Adicionalmente, entre os imigrantes, iniciar uma atividade empreendedora representa uma estratégia de integração laboral que possibilita ultrapassar a situação de desemprego, manter a profissão de origem, tornar rentáveis os recursos e competências que detêm, expandir os rendimento ou até gerar postos de trabalho, tanto para coétnicos como para familiares que se agrupam no país recetor (Coutinho et al., 2008). Porém, Kloosterman e Rath (2010) alertam para o facto de o empreendedorismo por parte de imigrantes de países menos desenvolvidos já não surgir como resultado de uma segunda opção após o emprego regular, mas sim como uma decisão, por se tratar de uma oportunidade atrativa.

Tedesco (2017) revela que o empreendedorismo é uma estratégia de mudança desenvolvida pelos imigrantes que permite a sua integração social e produtiva, mas cuja concretização não é conseguida com facilidade, uma vez que existem muitos limites, quer financeiros, quer burocráticos. Adicionalmente, Oliveira (2010) afirma que o facto de existirem constrangimentos, dificuldades e falta de oportunidades em Portugal, enquanto país de acolhimento, tem impacto nas escolhas dos imigrantes empreendedores. Nomeadamente, a falta de reconhecimento das qualificações dos imigrantes, os fracos conhecimentos linguísticos, bem como a discriminação, direcionam os imigrantes para o autoemprego, uma vez que são fatores que diminuem os retornos de um emprego remunerado (Lassmann \& Busch, 2015). No entanto, o empreendedorismo imigrante pode ser fomentado pelos enclaves étnicos, que representam uma vantagem comparativa nas necessidades específicas do grupo, proporcionando um ambiente autossustentável, uma vez que grandes enclaves podem fornecer uma oferta de mãode-obra coétnica mais barata (Lassmann \& Busch, 2015).

Importa ainda evidenciar que Oliveira (2005), através de um modelo heurístico, mostra como os imigrantes definem a sua estratégia empresarial, evidenciando que o facto de se tornarem empreendedores depende de três fatores: recursos pessoais, oportunidades étnicas e oportunidades estruturais. Os recursos pessoais estão relacionados com o nível de predisposição do imigrante para desenvolver diferentes atividades empresariais, dependendo igualmente do seu status legal no país de acolhimento; as oportunidades estruturais respeitam aos contextos económico, político e institucional da sociedade de acolhimento; e as oportunidades étnicas referem-se à comunidade imigrante, através da existência de determinados recursos étnicos e de uma possível economia interna, entre outros.

\subsection{Contributo do empreendedorismo imigrante no país recetor}

São inúmeras as preocupações existentes sobre o impacto da imigração no país de acolhimento, revelando-se fulcral compreender se o seu contributo líquido é positivo ou negativo (Fairlie \& Lofstrom, 2013). No caso do empreendedorismo imigrante, este proporciona um conjunto de vantagens para o país recetor, permitindo que empresários imigrantes possam «abrir mercados» através do conhecimento que detêm do seu país e das suas necessidades, tornando-se cruciais para a internacionalização de empresas portuguesas (Peixoto, 2008). Segundo Hatzigeorgiou (2010), o vasto conhecimento detido pelos imigrantes sobre a religião, a política, a cultura de negócios e a linguagem do seu país de origem, bem como a sua elevada 
rede de contactos, permite que estes assumam uma posição favorável ao estímulo do comércio com o seu país de origem, podendo desta forma encaminhar as empresas nacionais que objetivam a realização de comércio internacional. Adicionalmente, em Portugal, o empreendedorismo imigrante tem um impacto positivo no crescimento económico, permitindo a criação de novos postos de trabalho, quer para imigrantes quer para nativos, a inovação através de ideias, projetos e novas tecnologias que os imigrantes trazem consigo, a revitalização de zonas urbanas e, finalmente, mas não menos importante, uma evolução positiva dos métodos de inclusão social dos imigrantes (Coutinho et al., 2008; Peixoto, 2008). Peixoto (2008) defende ainda que um empreendedorismo imigrante bem-sucedido possibilita uma diminuição da carga financeira para o Estado, através da redução do desemprego e da tentativa de evitar o recurso a subsídios. Além disso, o contexto de reçeção revela-se um fator importante. Segundo Takenaka e Paerregaard (2015), é daí que advêm as oportunidades para os imigrantes desenvolverem/aplicarem as suas capacidades e recursos. Deste modo, o sucesso de uma atividade empreendedora resultará da combinação de fatores pessoais dos empreendedores (habilidades, competências, recursos) com as condições de mercado e questões regulatórias, de legislação e políticas (Rath \& Swagerman, 2016).

Face ao exposto, apesar das inúmeras vantagens supracitadas que o empreendedorismo imigrante pode proporcionar ao país recetor, existem obstáculos no país que dificultam a sua concretização. O mercado de trabalho na Europa apresenta-se fortemente regulado, levando à emergência de obstáculos ao empreendedorismo imigrante (Tubergen, 2005). Defendendo a OECD (2010) que as regulamentações de um país tornam dispendioso iniciar uma nova atividade, e uma vez que os imigrantes não estão tão familiarizados com as leis e as regulações do país de acolhimento, estes acabam por ter despesas maiores. Por sua vez, os elevados custos associados ao processo de arranque e a existência de procedimentos complexos relacionados com a execução de contratos, registo de propriedade ou outras questões legais podem levar à desistência por parte dos imigrantes de uma tentativa de ingresso no empreendedorismo (Lassmann \& Busch, 2015). Em Portugal, alguns dos mais recorrentes obstáculos são os legais e institucionais relacionados com os estatutos da imigração, o complexo acesso ao crédito, resultado da dificuldade de os imigrantes oferecerem determinadas garantias exigidas pelas instituições bancárias, bem como a dificuldade associada à abertura de contas, a falta de conhecimento sobre a legislação e o mundo dos negócios em Portugal, a dificuldade em ter acesso à informação ou o desconhecimento da língua (Coutinho et al., 2008; Peixoto, 2008). Ramos (2013a) evidencia ainda a discriminação e a exclusão como alguns dos constrangimentos enfrentados por minorias étnicas e comunidades de migrantes.

\subsection{Caracterização das vertentes do empreendedorismo imigrante}

\subsubsection{Género}

No total dos países da OCDE, a dimensão de mulheres empreendedoras entre nativos e nascidos no exterior é baixa, o que pode ser explicado pela combinação de uma baixa taxa de entrada no empreendedorismo por parte das mulheres com uma maior taxa de saída (Desiderio \& Salt, 2010). No entanto, entre 1998 e 2008, a proporção de mulheres imigrantes empreendedoras foi maior do que no caso das nativas, na maioria dos países da OCDE (Mestres, 2010). 
Os objetivos das mulheres na administração dos seus negócios vão além de medidas estritamente numéricas de sucesso empresarial, desejando criar uma ponte entre o trabalho e a vida familiar, visando o cumprimento de objetivos pessoais e profissionais, onde ganhar dinheiro é importante, mas a forma como os negócios contribuem para os seus valores, visões e desejos de equilíbrio entre a vida profissional e privada é igualmente crucial (Wang \& Morrell, 2015). Um emprego por conta de outrem em que existe incompatibilidade entre a gestão da vida familiar e o horário de trabalho pode conduzir a mulher para o autoemprego ou para situações que se definem como sendo empreendedoras (Ramos, 2013b).

\subsubsection{Nacionalidade}

A região de origem é um fator significativo na justificação das diferentes propensões ao empreendedorismo, mesmo existindo o controlo de um elevado conjunto de características individuais, isto porque as características do país de origem afetam a probabilidade de empreendedorismo, independentemente do país de destino (Tubergen, 2005; Desiderio \& Mestres-Domènech, 2011). Face ao exposto, as diferentes taxas de empreendedorismo entre grupos estrangeiros podem ser explicadas pelas distintas características de background (no que respeita a competências, entre outros), bem como pela proporção de empreendedores existentes no país de origem, que, sendo maior, leva a que indivíduos que migram desses países tenham uma maior propensão a estabelecer negócios no país recetor (Desiderio \& Salt, 2010). Adicionalmente, a existência de uma maior proporção de empreendedores no país de origem pode ser justificada pela sua cultura, isto é, se um imigrante vem de uma cultura empreendedora, a probabilidade de iniciar um negócio no país recetor é maior que a dos nativos, isto porque a cultura influencia a aversão ao risco e a capacidade de confiar nos outros, aspetos cruciais para a criação de um negócio (OECD, 2010).

Na União Europeia (UE), a maior parte da migração tem origem noutros países da UE, muitas vezes de novos países membros da parte oriental da Europa, sendo reconhecida como uma migração mais temporária; por sua vez, a migração a partir de fora da Europa para este continente é habitualmente realizada por países com uma história colonial e com uma língua comum (OECD, 2010). São os imigrantes asiáticos, com forte tradição trazida dos países de origem, quem tem uma maior propensão para se tornarem empreendedores em vários países da OCDE, nomeadamente em Portugal; por sua vez, os imigrantes da América Latina e de países africanos têm menos probabilidade de se estabelecerem como empreendedores, pois possuem menos recursos (Desiderio \& Salt, 2010; Malheiros \& Padilha, 2010). No entanto, verificamos, nos Quadros de Pessoal do Ministério do Trabalho, a importância dos empreendedores brasileiros em Portugal, tendo estes o conhecimento da língua portuguesa ou da língua do país de acolhimento.

\subsubsection{Setores/atividade}

Mestres (2010) evidencia que os empreendedores imigrantes, na sua maioria, trabalham fora dos setores considerados tradicionalmente como étnicos, isto é, setores que geralmente são associados a empresas de imigrantes, como é o caso do comércio grossista. O mesmo autor defende que o que se constata na Europa é uma concentração, tanto dos empreendedores imigrantes como dos nativos, em setores específicos, como o retalho, a construção, o alojamento, e menos em serviços de fabrico e apoio. Relevam-se as atividades em que os custos de arranque iniciais são relativamente baixos e não são requeridas qualificações específicas. 
Segundo Desiderio e Salt (2010), em Portugal os empreendedores imigrantes concentram-se em ocupações com baixas barreiras de entrada na atividade, como a construção, o comércio e a restauração.

\subsubsection{Idade e background familiar}

Segundo dados da Eurostat Labour Force Survey (cfr. Mestres, 2010), entre 1998 e 2008 três em cada quatro empreendedores imigrantes apresentavam uma idade superior a 35 anos. 0 mesmo autor advoga que numa comparação entre empreendedores e trabalhadores assalariados os empreendedores são em média mais velhos, uma vez que existe a necessidade de acumular capital social e físico, bem como a experiência necessária, antes de iniciar um negócio. Da mesma forma, também Coutinho et al. (2008) focam a importância da experiência na atividade empreendedora, uma vez que os imigrantes mais experientes, apesar de poderem desconhecer as especificidades do sistema português, assumem o empreendedorismo como uma possibilidade exequível e estão mais conscientes das condições de criação de uma empresa e dos benefícios que a formação do próprio emprego pode proporcionar. Adicionalmente, a existência de um background familiar empreendedor, como um pai, tem efeito na probabilidade de o filho se tornar igualmente empreendedor (Hout \& Rosen, 2000). Djankov et al. (2006) afirmam que no caso dos empreendedores é possível constatar a existência de aproximadamente três vezes mais familiares empreendedores, como um pai, irmão ou tio, comparativamente aos que não o são.

\subsubsection{Qualificações}

O background e as aptidões dos imigrantes influenciam o tamanho e a natureza dos negócios por si criados (OECD, 2010). Segundo Kloosterman e Rath (2010), com o aumento dos níveis de escolaridade os imigrantes de países menos desenvolvidos podem ser vistos a ingressar em negócios pertencentes a segmentos altamente qualificados, como consultoria de negócios ou serviços de software. A OCDE (2010) atesta ainda que imigrantes com baixas qualificações criam negócios por não terem outras alternativas de emprego, optando, por exemplo, por abrir uma pequena loja ou um restaurante, ingressando assim na criação de uma pequena empresa, onde há uma maior tendência para enfrentar taxas de mortalidade elevadas e baixos rendimentos. Por sua vez, os imigrantes qualificados realizam empreendimentos destacados, como empresas de alto crescimento, que representam a maior parte do aumento do emprego em muitos países da OCDE, uma vez que criam negócios que crescem rapidamente com o objetivo de se tornarem numa grande empresa (OECD, 2010). Assim, é possível, no caso dos imigrantes, estabelecer-se uma relação em forma de " $U$ " entre ser empreendedor e a formação escolar, tornando-se os imigrantes com menores qualificações e com poucas opções de trabalho mais propensos a criar o seu próprio negócio (OECD, 2010). Porém, Malheiros e Padilha (2010) defendem que em Portugal se verificam as teorias que ditam que, com o aumento do nível de educação, aumenta também a propensão para o empreendedorismo.

Segundo dados da Eurostat Labour Force Survey (cfr. Mestres, 2010), entre 1998 e 2008, em todos os países da OCDE, $30 \%$ a $40 \%$ dos empreendedores imigrantes apresentavam um nível de educação elevado, exceto em Itália e em Portugal, onde a escolaridade se mostrou geralmente mais baixa. Adicionalmente, dentro dos empreendedores mais qualificados, os imigrantes apresentavam uma proporção maior relativamente aos nativos, e enquanto Portugal (50\%) e Itália (40.2\%) se revelaram dois países com uma elevada proporção de empreendedores 
imigrantes com baixas qualificações, outros países exibiam o contrário, como a Áustria (13.1\%), a Polónia (8.8\%) e a Hungria (6.2\%) (Mestres, 2010). Face ao exposto, a teoria defendida por Malheiros e Padilha (2010) é contrariada pelos dados da Eurostat Labour Force Survey (cfr. Mestres, 2010), visível na Figura 1, uma vez que a proporção de empreendedores, quer imigrantes quer nativos em Portugal, entre 1998 e 2008, aumenta com a diminuição do nível de qualificação.

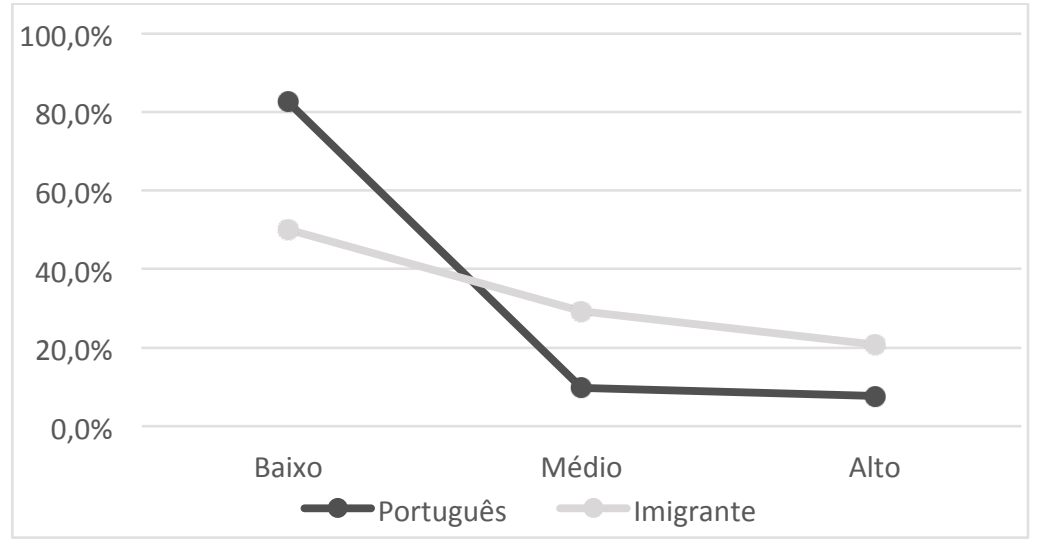

Figura 1: Nível de educação dos empreendedores portugueses e imigrantes em Portugal entre 1998-2008.

Fonte: Elaboração própria baseada em Mestres (2010).

\section{METODOLOGIA}

A presente investigação pretende obter uma compreensão mais aprofundada do perfil do empreendedor imigrante em Portugal, através das categorias sexo, idade, nacionalidade, qualificação e atividade, e conhecer o impacto que este empreendedor pode ter no país, pelo que a metodologia qualitativa revelou-se ser a mais adequada. Permitindo a exploração de um enorme conjunto de dimensões do mundo social, como a experiência, o entendimento e a imaginação dos participantes (Mason, 2002), esta metodologia, através da realização de entrevistas aprofundadas, permite explorar o conhecimento, a perceção, a experiência e a interação das pessoas, características que se assumem neste método qualitativo como importantes da realidade social (Mason, 2002).

Para o efeito, recorreu-se à entrevista semiestruturada, um tipo de entrevista que se caracteriza por ser aprofundada com recurso a um guião, no qual se procurou compreender o perfil e o percurso pessoal e profissional dos empreendedores imigrantes contactados residentes no Norte de Portugal. Através deste método, foi possível realizar um conjunto de 12 entrevistas, nove a indivíduos do sexo masculino e três do sexo feminino, nascidos em seis países diferentes, nomeadamente no Brasil, Bangladesh, China, Rússia, Ucrânia e Índia, no período de fevereiro a março de 2017. Houve ainda a possibilidade de entrevistar dois presidentes de associações de imigrantes, um de nacionalidade russa e o outro chinês.

Importa ainda salientar que, num estudo sobre imigração, se evidenciou a diferença cultural entre grupos de imigrantes, bem como a diferença cultural existente entre os imigrantes e o país de acolhimento (Vinogradov, 2011), como foi possível constatar nas entrevistas. Assim, a questão cultural revelou-se uma barreira na recolha dos dados, uma vez que existiram empreendedores imigrantes que rejeitaram colaborar, como foi o caso dos chineses, e outros 
que colaboraram, contudo com um discurso claramente mais fechado do que, por exemplo, o dos brasileiros.

\section{RESULTADOS E DISCUSSÕES}

\subsection{Motivos para empreender em Portugal}

Ramos (2007) sugere que o empreendedorismo imigrante pode encaminhar os imigrantes para o sucesso e contribuir para a sua inserção no país recetor, podendo também surgir como forma de suprir as dificuldades, nomeadamente as de ingressar no mercado de trabalho. Deste modo, torna-se pertinente conhecer o motivo que levou os imigrantes entrevistados a empreender em Portugal. Como é possível observar na tabela infra, as respostas não se dispersaram muito: $50 \%$ dos entrevistados tiveram sempre como objetivo empreender, tendo sido essa vontade que os levou a criar um negócio próprio; $33 \%$ empreenderam porque surgiu a oportunidade; e $17 \%$ porque tiveram essa necessidade.

Tabela 1: Motivo para empreender em Portugal.

\begin{tabular}{|l|l|l|l|}
\hline \multirow{2}{*}{ Entrevistados } & \multicolumn{3}{|l|}{ Subcategorias } \\
\hline & Necessidade & Objetivo & Oportunidade \\
\hline A.K. & & & \\
\hline A.M. & & & \\
\hline B.S. & & & \\
\hline C.S. & & & \\
\hline D.S. & & & \\
\hline L.M. & & & \\
\hline M.A. & & & \\
\hline M.J. & & & \\
\hline N.Y. & & & \\
\hline R.C. & & & \\
\hline V.G. & & & \\
\hline Y.C. & & & 33 \\
\hline Total (\%) & 17 & 50 & \\
\hline \multicolumn{4}{|c|}{ Fonte: Elaboração própria } \\
\hline
\end{tabular}

Estes resultados vão ao encontro dos dados existentes na literatura, nomeadamente os de Coutinho et al. (2008), que verificaram que alguns dos motivos que levavam os imigrantes a empreender no país recetor eram, entre outros, o desemprego e a manutenção da profissão do país de origem, e os de Kloosterman e Rath (2010), afirmando que imigrantes de países menos desenvolvidos empreendem no país de acolhimento por decisão, por se tratar de uma boa oportunidade, e não como uma segunda opção. 


\subsection{Contibutos do empreendedorismo imigrante no país de acolhimento}

A presente investigação permitiu verificar a tendência dos imigrantes para estabelecer um relacionamento com o seu país de origem. Dos 12 entrevistados, dois visionam crescer a nível internacional, nomeadamente para o seu país de origem, e três, apesar de não partilharem da mesma ambição, mantêm contacto com o seu país de origem (nomeadamente o Brasil, a Índia e a Rússia). Desta forma, foi possível ir ao econtro de Hatzigeorgiou (2010), que defende que os imigrantes, através do conhecimento que detêm do seu país de origem, acabam por estimular as relações comerciais entre este e o país de acolhimento.

No que respeita à criação de postos de trabalho (Tabela 2), a maioria dos entrevistados (50\%) revelou não ter empregados, no entanto apenas um não ambiciona contratar, por se tratar de um negócio familiar, demonstrando os restantes essa vontade. É de notar que, ao empregar trabalhadores familiares e/ou da comunidade de origem, os imigrantes conseguem reduzir os custos da atividade empresarial. Importa ainda referir que um dos entrevistados, à data da realização da entrevista, se encontrava ainda a finalizar o seu projeto, pelo que a razão de não ter empregados se prende com o facto de ainda não ter criado o seu negócio, não se enquadrando desta forma em nenhuma subcategoria de análise, uma vez que ao iniciar a sua atividade terá de contratar, como é possível observar no comentário que se segue:

- Eu ainda não abri nenhum empreendimento, mas a churrasqueira vai ter 3 colaboradores. O ginásio sempre precisa de pessoas para dar aulas, mais ou menos 5/6, e mais pessoas para limpar, mas aí ainda não tenho nada muito definido. E para ser muito sincero, prefiro trabalhar com portugueses. L.M.

Os restantes cinco entrevistados já criaram postos de trabalho, na sua maioria para indivíduos que, como eles, também imigraram.

Tabela 2: Criação de postos de trabalho.

\begin{tabular}{|l|l|l|l|}
\hline \multirow{2}{*}{ Entrevistados } & \multicolumn{3}{|c|}{ Subcategorias } \\
\cline { 3 - 4 } & \multicolumn{2}{|c|}{$\begin{array}{c}\text { Não tem } \\
\text { empregados }\end{array}$} & \multicolumn{2}{|c|}{ Tem empregados } \\
\cline { 3 - 4 } A.K. & & & \\
\hline A.M. & & & \\
\hline B.S. & & & \\
\hline C.S. & & & \\
\hline D.S. & \multicolumn{2}{|c|}{ Portugueses } \\
\hline L.M. & \multicolumn{2}{|c|}{ A desenvolver o projeto } \\
\hline M.A. & \multicolumn{3}{|l}{} \\
\hline M.J. & & & \\
\hline N.Y. & & & \\
\hline R.C. & & & \\
\hline V.G. & & 33 & \\
\hline Y.C. & 50 & & \\
\hline Total (\%) & & & \\
\hline
\end{tabular}

Fonte: Elaboração própria. 
Efetivamente, estes resultados seguem no sentido da realidade defendida por Coutinho et al. (2008) e Peixoto (2008), confirmando que o empreendedorismo em Portugal realizado por imigrantes de países em desenvolvimento é propício à criação de postos de trabalho, tanto para imigrantes como para nativos, uma vez que, dos entrevistados, 92\% visa empregar/empregou alguém. Importa assim evidenciar que, dos empreendedores que não têm empregados mas tencionam contratar, quatro não têm preferência na escolha, podendo optar tanto por portugueses como por imigrantes, e dois são claros quanto a querer contratar portugueses. Por sua vez, dos que já geraram emprego, 33\% optaram por contratar imigrantes e apenas $8 \%$ (um entrevistado) contratou portugueses, como é possível verificar no quadro supracitado. Podemos notar subsequentemente alguns extratos de entrevistas relativamente a este aspeto:

- Tenho dois trabalhadores, a daqui é ucraniana e em Braga também. Para mim, é importante criar emprego e, como precisava de ajuda, contratei uma pessoa para cada loja, mas também me importa ajudar os que como eu imigraram à procura de oportunidades, por isso é que não são portugueses. (Contratou imigrantes) D.S.

- Trabalho sozinho, criei um sistema de trabalho para mim, quando montei esta empresa, que informatizei de tal forma a coisa, que não há necessidade para já. A empresa vem crescendo ano a ano e vai chegar uma hora que eu vou precisar, e a precisar, contrataria portugueses, no fundo para devolver um pouco daquilo que recebi. (Objetiva contratar) M.J.

Coutinho et al. (2008) e Peixoto (2008) reconhecem ainda a possibilidade de os empreendedores imigrantes deterem novas ideias, projetos ou tecnologias, permitindo que o país inove. Desta forma, os entrevistados foram questionados relativamente ao que consideram como características e/ou conhecimentos distintos que pudessem ter em relação aos trabalhadores portugueses, com vista a conhecer potenciais inovações para o país de acolhimento:

- $17 \%$ consideram não ter conhecimentos/competências distintos dos portugueses;

- $83 \%$ acreditam existirem conhecimentos/competências distintos:

- Seis dos entrevistados acreditam que são os aspetos culturais que os distinguem dos portugueses, nomeadamente os brasileiros (três dos entrevistados em questão), que reconhecem a abertura dos portugueses à novidade e para com o outro um elemento distintivo;

- Outros três reconhecem a experiência de vida como elemento causador da diferença.

\subsection{Envolvimento com o país de acolhimento e o associativismo}

Importa agora conhecer o envolvimento dos imigrantes empreendedores com associações existentes no país de acolhimento, demonstrando assim a sua implicação na vida económica e social do mesmo. Além de Ramos (2013b) evidenciar a importância de integração dos imigrantes no país recetor, Malheiros e Padilha (2010) focam a importância que as associações têm, uma vez que servem de elemento de ligação entre os imigrantes e o país de acolhimento. Ramos \& Ramos (2014) defendem ainda que as associações de migrantes, além de representarem espaços importantes de socialização, permitem igualmente, através do comércio, do regionalismo e da utilização de redes familiares, de vizinhança e de amizade, participar nas 
realidades sociais, culturais, políticas e económicas, quer dos países de emigração, quer dos de imigração.

Quando questionados sobre 0 seu envolvimento com associações empresariais/imigrantes, $67 \%$ revelaram não ter nenhum envolvimento, estando os restantes $33 \%$ envolvidos, como se pode observar nos extratos abaixo:

- Sim, sou vice-presidente da associação empresarial de Viana do Castelo. M.J.

- Sim, com a AMIZADE. N.Y.

- Sim, com a Associação de Apoio aos Imigrantes. V.G.

- Sou o presidente da Liga dos Chineses em Portugal. Y. P. C.

Ramos (2007) evidencia que a integração dos imigrantes no país de acolhimento com vista a reforçar a coesão social deve constituir um dos principais focos da política europeia de imigração, sendo importante um forte investimento nesta vertente. Deste modo, sendo as associações um dos meios propícios à integração dos imigrantes no país de acolhimento, interessa fomentar a relação entre os imigrantes e as associações (Malheiros \& Padilha, 2010), uma vez que, de entre os 12 entrevistados, apenas quatro assinalaram a existência de algum envolvimento.

No sentido de perceber melhor como podem os imigrantes ter conhecimento das associações existentes e de qual o apoio prestado por estas, questionou-se os presidentes da Associação de Apoio ao Imigrante e da Liga dos Chineses em Portugal, demonstrando que para tomar conhecimento é necessário procurarem:

- Nós temos o site da Associação de Apoio ao Imigrante e, como fomos os primeiros, desde 2002, algumas fábricas tiveram acesso, através da junta de freguesia, em São Bernardo, à nossa organização e já daqui há alguma fama. Algumas pessoas chegam de Lisboa e perguntam onde está a rua São Bernardo. Eu fiz muitas entrevistas em todos os canais de televisão, por isso somos conhecidos já. As pessoas já sabem quem nós somos, ou facilmente encontram quando procuram.

\section{Presidente da Associação de Apoio ao Imigrante}

- Há sempre um empenho no trabalho da associação para se dar a conhecer, mas tudo depende das pessoas. As pessoas não procuram assim uma associação. Quando os imigrantes procuram a associação é porque precisam de ajuda, e este não é o caso dos chineses, tendem a resolver tudo sozinhos, sem pedir auxílio. Presidente da Liga dos Chineses em Portugal

Ainda no que respeita ao apoio prestado pelas associações ao empreendedorismo, uma das associações revelou ter já trabalhado nessa área; outra, por sua vez, foca-se mais na integração, e não tanto no incentivo/apoio ao empreendedorismo:

- Acho muito importante, e claro que temos interesse em ajudar nisso. Nós podemos fazer várias sessões, várias atividades. Mas nós somos exigentes, não precisamos de formadores que não sabem nada. Eu própria avalio: se é uma formadora que sabe menos que eu, então eu não admito isso. Se não sabe explicar, dizer como a pessoa pode criar um negócio, ou se só sabe teoricamente, então não dá, não precisamos de formadores desse tipo, precisamos de pessoas com experiência, que podem dizer, mostrar. Nós já criámos uma parceria com uma empresa onde o senhor que era dono da empresa era testemunha e mostrou todos os passos, já convidámos elementos das finanças, do desemprego, tudo, cada instituição tem de explicar as suas exigências 
para as pessoas conseguirem ultrapassar as dificuldades que vão encontrar, não queremos sessões teóricas. Presidente da Associação de Apoio ao Imigrante

- A Liga dos Chineses é uma associação um pouco diferente, porque tem a participação de outras associações. A nossa associação tem como objetivo ajudar a integração e criar as relações com os portugueses, ou até mesmo com as entidades portuguesas. É nesse sentido que vai a nossa ajuda. Presidente da Liga dos Chineses em Portugal

Face ao exposto, identifica-se uma oportunidade de melhoria a este nível, sendo vários os autores que reconhecem a importância do envolvimento dos imigrantes com as associações de imigrantes e empresariais, pelo que, ao afinar a forma de se tomar conhecimento das mesmas e dos seus apoios, se poderia melhorar o sucesso dos empreendimentos de imigrantes, bem como a integração dos mesmos no país de acolhimento. Segundo Ramos e Ramos (2014), é necessário que a atuação das associações seja feita em rede (local, nacional e transnacional), visando uma maior articulação das necessidades e dos interesses dos imigrantes.

\subsection{Características dos empreendedores imigrantes}

A amostra é limitativa quanto à possibilidade de tirar conclusões relativamente à vertente género, educação e nacionalidade dos empreendedores. Porém, pelos casos que constituem a amostra, é possível verificar uma participação claramente marcada por indivíduos do sexo masculino (75\%), uma vez que não surgiram mais mulheres empreendedoras dispostas a colaborar. No que respeita ao fator educação, todos os entrevistados possuem o 12. ano, tendo quatro deles concluído igualmente a licenciatura, dois o mestrado e encontrando-se um a realizar doutoramento, o que contraria a literatura defendida pela OECD (2010) e por Mestres (2010), em que a propensão dos imigrantes para o empreendedorismo aumenta quanto menor for a sua qualificação, porém a presente amostra vai ao encontro de Malheiros e Padilha (2010), que atestam um cenário oposto em Portugal. Importa ainda evidenciar que desta amostra emerge uma elevada presença de empreendedores brasileiros, uma vez que se mostraram mais dispostos a colaborar e que todos os entrevistados imigraram de países fora da União Europeia.

Quanto à idade, os entrevistados foram questionados no sentido de perceber se existe alguma influência do fator experiência. De facto, Coutinho et al. (2008) acreditam que, apesar de os imigrantes poderem desconhecer determinados aspetos do sistema português, o facto de serem mais experientes leva-os a considerarem o empreendedorismo como uma hipótese viável. Como se pode verificar na figura infra, os dados vão ao encontro da literatura: do total de entrevistados, $42 \%$ criaram o seu primeiro empreendimento enquanto imigrantes com idades entre os 40 e os 44 anos, sendo que um dos entrevistados ainda não concretizou o seu empreendimento, mas, segundo o seu projeto, fá-lo-á até ao final do ano, iniciando-o com 41 anos; com $25 \%$, seguem-se os imigrantes que empreenderam com idades compreendidas entre os 35 e os 40 anos. Importa ainda referir que o imigrante que empreendeu em Portugal com idade entre os 15 e 19 anos foi o entrevistado Y. C., que desde sempre teve os seus negócios em Portugal, uma vez que imigrou com sete anos. Ainda a título informativo, os entrevistados que empreenderam com idades entre 25 e 34 anos e um indivíduo que empreendeu com 38 anos já eram empreendedores no seu país de origem, o que levou a que, enquanto imigrantes, também o desejassem fazer. 


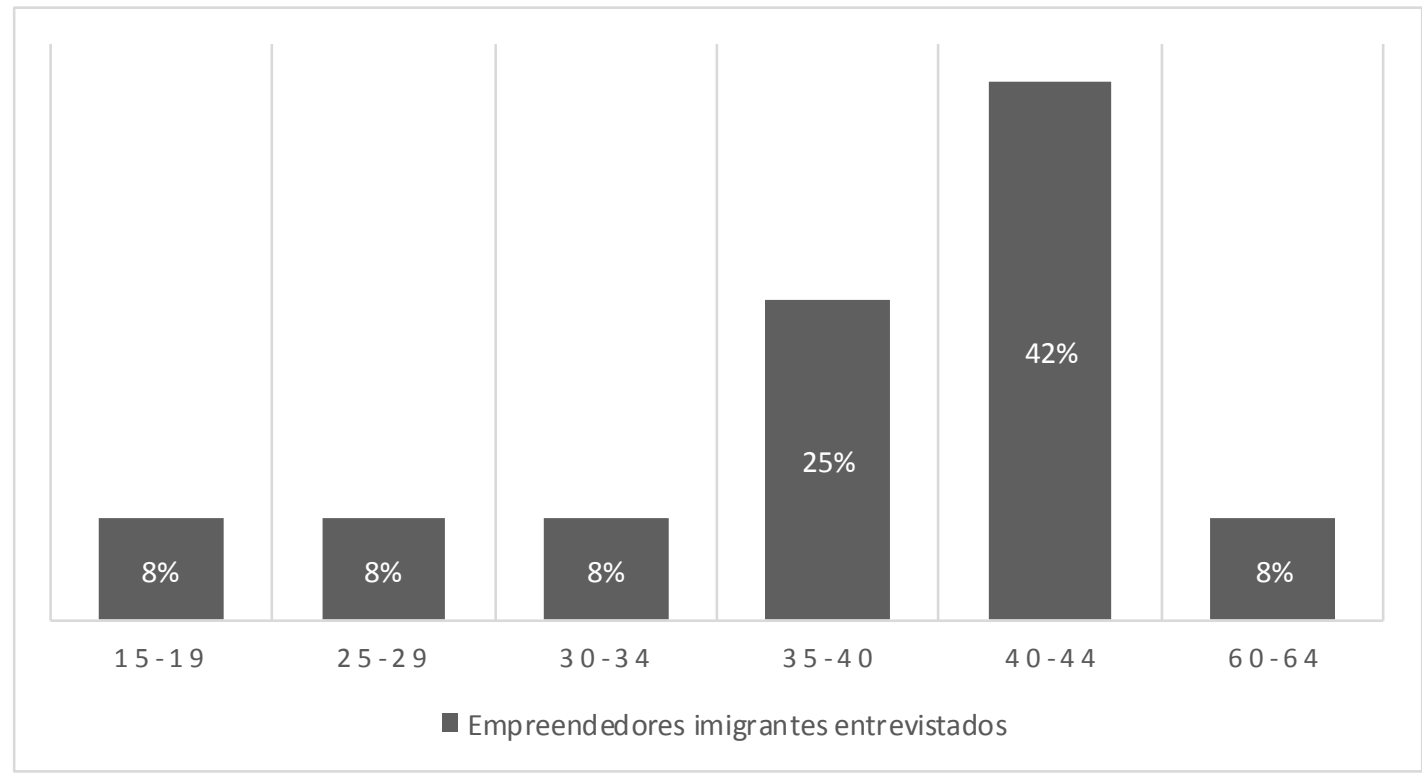

Figura 2: Distribuição de idades com que os imigrantes entrevistados empreenderam (\%). Fonte: Elaboração própria.

No que respeita ao background familiar, $25 \%$ dos entrevistados afirmaram não terem ninguém na família empreendedor, no entanto os restantes $75 \%$ revelaram existirem familiares também eles com uma tendência empreendedora. Destes 75\% (nove entrevistados):

- Três acreditam que a tendência familiar para o empreendedorismo não os influenciou a também eles se tornarem empreendedores e, tal como abaixo citado, afirmam ter sido uma vontade própria:

- Quase a minha família toda é empreendedora, mas acho que não me influenciou, sempre foi uma vontade minha. A.K.

- Sim, tenho um tio empreendedor, com 30/40 anos. Não sei se influenciou de alguma forma, eu sempre tive esta vontade, é de mim. M.A.

- A minha filha, os meus pais e todos os meus primos têm os seus próprios negócios, mas isso não me influenciou, isto sempre foi a minha própria vontade.

Y. C.

- Os restantes seis acreditam que existe uma influência positiva dessa tendência familiar:

- Sim, os meus pais, eles tiveram um minimercado a vida toda, se sustentaram assim, com o minimercado deles. Sim, sinto que de alguma forma me influenciou pela vontade que tenho de ter sucesso num negócio que é meu. A.M.

- Tenho um tio empreendedor. Acho que sim, me influenciou, ver o meu tio com o seu negócio próprio acabou por me inspirar um bocado. B.S.

- Mais diretamente, tenho irmãos. Talvez, não sei, ver o negócio deles correr bem também me fez acreditar que comigo seria igual, tinha era de tentar. C.S. 
Desta forma, verifica-se que os dados seguem no sentido da literatura. Assim, como defendido por vários autores, existe uma influência do background familiar no empreendedorismo imigrante (Hout \& Rosen, 2000; Djankov et al., 2006).

Adicionalmente, tornou-se relevante perceber o porquê de os entrevistados decidirem empreender num setor específico. Segundo Mestres (2010), na Europa os empreendedores imigrantes concentram as suas atividades mais em setores como a construção, o retalho e o alojamento, e não tanto em setores denominados étnicos, como os serviços de fabrico e apoio. Por sua vez, a amostra em estudo concentra-se essencialmente nos setores do retalho e da prestação de serviços, não indo totalmente ao encontro da literatura, o que torna importante perceber o que justifica essa concentração. Como a tabela abaixo evidencia, $42 \%$ dos entrevistados justificam a escolha do setor por já terem experiência nesse ramo, seguindo-se a oportunidade, com 25\%; as restantes justificações, gosto, networking, satisfação da necessidade do mercado, apresentam igual distribuição (17\%).

Tabela 3: Motivos da escolha do setor.

\begin{tabular}{|c|c|c|c|c|c|}
\hline \multirow[b]{2}{*}{ Entrevistados } & \multicolumn{5}{|c|}{ Subcategorias } \\
\hline & Experiência & Gosto & Networking & $\begin{array}{c}\text { Satisfação da } \\
\text { necessidade do } \\
\text { mercado }\end{array}$ & Oportunidade \\
\hline A.K. & & & & & \\
\hline A.M. & & & & & \\
\hline B.S. & & & & & \\
\hline C.S. & & & & & \\
\hline D.S. & & & & & \\
\hline L.M. & & & & & \\
\hline M.A. & & & & & \\
\hline M.J. & & & & & \\
\hline N.Y. & & & & & \\
\hline R.C. & & & & & \\
\hline V.G. & & & & & \\
\hline Y.C. & & & & & \\
\hline Total (\%) & 42 & 17 & 17 & 17 & 25 \\
\hline
\end{tabular}

Fonte: Elaboração própria.

Vários autores reconhecem a existência de obstáculos em Portugal ao empreendedorismo imigrante, ressaltando, entre outros, a forte regulamentação, os elevados custos de arranque, o difícil acesso ao crédito, a falta de conhecimento sobre a legislação e o mundo de negócios e a língua, bem como o difícil acesso à informação (Tubergen, 2005; Coutinho et al., 2008; Peixoto, 2008; Lassmann \& Busch, 2015). Desta forma, os entrevistados foram questionados no sentido de perceber se identificam igualmente como obstáculos os aspetos supracitados e quais as vantagens que consideram ter com o seu empreendimento em Portugal. 
Tabela 4: Vantagens e obstáculos.

\begin{tabular}{|c|c|c|c|c|c|c|c|c|c|}
\hline \multirow{2}{*}{ Entrevistados } & \multicolumn{4}{|c|}{$\begin{array}{c}\text { Subcategorias das } \\
\text { vantagens }\end{array}$} & \multicolumn{5}{|c|}{ Subcategorias dos obstáculos } \\
\hline & Facilidade & Independência & Custos & putros & Burocracia & \begin{tabular}{|c|} 
Falta de \\
conhecimento
\end{tabular} & Língua & Mentalidade & Outros \\
\hline A.K. & & & & & & & & & \\
\hline A.M. & & & & & & & & & \\
\hline B.S. & & & & & & & & & \\
\hline C.S. & & & & & & & & & \\
\hline D.S. & & & & & & & & & \\
\hline L.M. & & & & & & & & & \\
\hline M.A. & & & & & & & & & \\
\hline M.J. & & & & & & & & & \\
\hline N.Y. & & & & & & & & & \\
\hline R.C. & & & & & & & & & \\
\hline V.G. & & & & & & & & & \\
\hline Y. C. & & & & & & & & & \\
\hline Total (\%) & 25 & 75 & 25 & 33 & 50 & 33 & 42 & 17 & 42 \\
\hline
\end{tabular}

Fonte: Elaboração própria.

Na tabela supra, é possível verificar-se que as respostas dos entrevistados estão em linha com a literatura defendida pelos autores acima referidos: a maioria (50\%) identifica a burocracia como principal obstáculo, seguindo-se a língua (42\%). 42\% apontam ainda como obstáculos um conjunto de aspetos distintos, que vão desde o acesso ao crédito, mentira, falta de iniciativa, diferenças culturais e a polaridade, como podemos ler nos extratos que se seguem:

- A falta de iniciativa, pois tem muitas pessoas que preferem não trocar o certo pelo duvidoso e buscam empregos, ao invés de empreender. A.M.

- A principal dificuldade de criar um negócio aqui, no meu caso, foi aprender a lidar com clientes, mas depois aprendemos. A.K.

- A questão da polaridade: aqui os negócios estão em dois polos, em Lisboa e no Porto, então quando se vai abrir uma loja física, pelo menos no meu segmento, acabamos por não ter muitas opções para abrir. C.S

- A dificuldade de acesso a crédito. M.J.

- Vendedores dos negócios mentem, infelizmente. V.G.

Importa ainda evidenciar que uma das entrevistadas revelou não ter sentido dificuldades, uma vez que o marido é português e o cunhado já era empreendedor em Portugal.

Adicionalmente, quando questionada a presidente da Associação de Apoio ao Imigrante sobre eventuais obstáculos que os empreendedores imigrantes enfrentam, esta prontamente respondeu:

- Têm dificuldades só no início, por causa da língua, porque nenhum imigrante consegue saber $100 \%$ a língua nova e é preciso, para saber alguns detalhes sobre a lei ou, por exemplo, na 
apresentação dos projetos. Os imigrantes que estão inscritos no desemprego sabem que têm direito ao dinheiro que o Estado tem de dar mensalmente e podem com esse dinheiro abrir um negócio. Eu conheço um casal que pegou no dinheiro todo e depois não sabia certos pormenores e não conseguiu manter o negócio; depois eles ganharam experiência, mas no início foi muito difícil, tiveram muitos gastos a regular a situação. Presidente da Associação de Apoio ao Imigrante

Desta forma, a entrevistada concorda que os imigrantes acabam por enfrentar maiores custos ao iniciar uma atividade, uma vez que não estão acostumados com as leis e os regulamentos do país, o que confirma as conclusões da OCDE (OECD, 2010).

No que respeita às vantagens, $75 \%$ dos entrevistados afirmam que serem independentes é a maior vantagem de empreender, seguindo-se, com 33\%, um conjunto de outros fatores, como a responsabilidade que alavanca a ambição, a burocracia, tirar partido das relações com o país de origem e a segurança, como se pode corroborar com alguns comentários dos entrevistados abaixo apresentados:

- Em termos de legislação, é mais fácil do que no Brasil, menos burocrático. A.M.

- Depois, supondo que o empreendedor é bem-sucedido, no Brasil [...] não tem tranquilidade ao longo do dia de trabalho, existe toda esta violência. Aqui existe uma enorme segurança e paz, que é o que um empreendedor procura, seja ele bem-sucedido ou não. L.M.

- Ser empreendedor também tem muitas mais responsabilidades e preocupações, e eu acho que é isso que acaba por alavancar o negócio, a partir do momento que se tem uma coisa muito certinha, parece que falta ambição, e quando se tem o seu próprio negócio e tem que fazer o negócio crescer, a ambição também prevalece. A boa ambição. M.J.

- Ao ser um chinês que conhece melhor a China e que sabe o que os portugueses não têm, é uma vantagem ser empreendedor, eu sei e decido que produtos posso trazer de lá e que cá não há, ou que consigo trazer a melhor preço. Y. C.

Foi possível identificar que, depois de imigrarem e de ultrapassados os principais obstáculos, os imigrantes criam um elo com o país de acolhimento que os faz querer permanecer em Portugal, negando a hipótese de voltar para o seu país de origem ou até de reemigrarem.

Por fim, tornou-se pertinente perceber que a maioria (67\%) dos entrevistados aconselharia empreender em Portugal, desde que se tenham determinados cuidados antes de o fazer, como ter experiência profissional, meios financeiros, responsabilidade e, acima de tudo, estudar bem o mercado e a cultura do país. Por sua vez, 33\% não aconselham, determinando que primeiro é importante trabalhar para outrem, para assim conhecer mais detalhes do país de acolhimento. Veja-se os seguintes exemplos:

- Eu diria para pesquisar antes de abrir qualquer negócio. Eu conheço muita gente que tem interesse em vir para Portugal, até pelas condições políticas no Brasil, e eu digo assim: todo o negócio é bom, mas tem que ser de acordo com o que você gosta de fazer, com o que você quer fazer e quanto você tem para investir. Mas minha primeira resposta é sim, é viável abrir um negócio, mas tem que pesquisar as condições de negócio em si. C.S. 
- Sim, aconselhava e ajudava. Dizia, por exemplo, para onde tem de ir, para fazer licenças, para ir às finanças; eu ligava e ajudava, ou ia lá com ele, porque quando chegamos cá não sabemos nada de português, e eu ajudava para falar. D.S.

- De imediato não, aconselhava a primeiro ingressar num trabalho por conta de outro, porque primeiro tem de aprender, ver como as coisas funcionam, se gosta ou não gosta, é preciso esse tempo. M.A.

\section{CONCLUSÕES}

O objetivo primordial da presente investigação foi o de compreender como se caracteriza o empreendedorismo imigrante e qual o seu impacto num país de acolhimento como Portugal, país onde os estudos nesta temática são ainda limitados. Assim, através da amostra que foi possível obter, constituída apenas por imigrantes de países de fora da União Europeia (UE), realizou-se uma distinção por género, idade, nacionalidade, educação e setores/atividades e procurou-se analisar o impacto e perceber os contributos que os imigrantes enquanto empreendedores podem dar ao país de acolhimento, tendo em consideração as barreiras que lhes são impostas, bem como o envolvimento destes com o país.

No que respeita às características, género e educação, embora os dados e opiniões recolhidos sejam limitados, da amostra emerge uma maior presença de empreendedores imigrantes homens (75\%) e com escolaridade completa ao nível do ensino secundário (todos os entrevistados), tendo $58 \%$ continuado os estudos no ensino superior. Quanto à nacionalidade, dos dados relativos aos empreendedores imigrantes, obtidos através das entrevistas, com uma amostra de indivíduos de países exteriores à UE, é evidente uma forte presença de brasileiros, fruto de uma questão cultural e linguística, mostrando-se estes mais predispostos a colaborar nas entrevistas. Foi ainda possível identificar que os entrevistados empreenderam essencialmente no setor do retalho e da prestação de serviços e justificaram a escolha do setor com o facto de já terem experiência nesse ramo (42\%), de ter surgido a oportunidade (25\%), ou ainda, com igual distribuição (17\%), por uma questão de gosto, networking, satisfação da necessidade do mercado. Por fim, quanto à idade, a maioria dos entrevistados (42\%) criou o seu primeiro empreendimento enquanto imigrante com idades entre os 40 e os 44 anos, confirmando a importância do fator experiência para um imigrante empreender no país de acolhimento. Da mesma forma, de entre os entrevistados com elementos na família com tendência empreendedora (nove), a maioria (seis) revelou acreditar na influência positiva que a existência de um background familiar tem.

Quanto ao último aspeto da investigação, o contributo do empreendedorismo imigrante, 92\% dos entrevistados visam empregar/empregam alguém, constatando que a amostra é propícia à criação de postos de trabalho. Adicionalmente, $42 \%$ desenvolvem/visam desenvolver comércio com o seu país de origem. Ainda sobre a possibilidade de os empreendedores imigrantes deterem novas ideias, projetos ou tecnologias, a maioria dos entrevistados (83\%) acredita que existem conhecimentos/competências distintos, nomeadamente fruto de aspetos culturais ou da experiência de vida. De entre os obstáculos destacados pelos entrevistados, encontram-se: o acesso ao crédito, a mentira, a falta de iniciativa, as diferenças culturais, a polaridade, a mentalidade, a falta de conhecimento, a língua e a burocracia. Por sua vez, no que respeita às vantagens, os entrevistados enunciam: a responsabilidade que alavanca a ambição, o 
tirar partido das relações com o país de origem, a segurança, os baixos custos, a facilidade e a independência.

Assim, foi possível estabelecer um quadro atual e pormenorizado de como se caracteriza o empreendedorismo imigrante em Portugal e do seu consequente contributo para o desenvolvimento da economia, da inovação e da internacionalização do país. Adicionalmente, foi importante perceber a necessidade que existe em fomentar a relação entre os imigrantes e as associações, sendo esta uma das medidas para a integração dos imigrantes prevista pelo Governo de Portugal (2015) no Plano Estratégico para as Migrações 2015-2020, uma vez que, de entre os 12 entrevistados, apenas quatro demonstraram a existência de algum envolvimento com associações empresariais e de imigrantes.

\section{REFERÊNCIAS}

Ahmad, N., \& Seymour, R. G. (2008). Defining Entrepreneurial Activity: Definitions Supporting Frameworks for Data Collection OCDE.

Baycan-Levent, T., \& Nijkamp, P. (2009). Characteristics of migrant entrepreneurship in Europe. Entrepreneurship \& Regional Development, Vol. 21, No. 4, 375-397.

Caetano, A. et al. (2014). GEM Portugal 2013 / 2004-2013: Uma Década de Empreendedorismo em Portugal. Global Entrepreneurship Monitor. Lisboa: ISCTE-IUL; SPI.

Coutinho, A. L., Oliveira, B., Soares, V. \& Sanchez, S. M. (2008). O empreendedorismo imigrante em Portugal: factores que influenciam este percurso profissional e actividade da ASI decorrente dos resultados do projecto PEI. Revista Migrações, No. 3, 263-270.

Desiderio, M. V., \& Salt, J. (2010). Main Findings of the Conference on Entrepreneurship and Employment Creation of Immigrants in OECD Countries, 9-10 June 2010, Paris. Open for Business: Migrant Entrepreneurship in OECD Countries, OECD Publishing.

Desiderio, M. V., \& Mestres-Domènech, J. (2011). Migrant Entrepreneurship in OECD Countries. In International Migration Outlook: SOPEMI 2011 (Ed.), Part II, pp. 139-203, OECD.

Djankov, S., Qian, Y., Ronald, G. \& Zhuravskaya, E. (2006). Who are China's Entrepreneurs?. The American Economic Review, Vol. 96, No. 2, 348-352.

Fairlie, R. W., \& Lofstrom, M. (2013). Immigration and Entrepreneurship Discussion Paper No. 7669. Bonn: IZA.

Fee, L. K., \& Rahman, M. M. (2014). From Workers to Entrepreneurs: Development of Bangladeshi Migrant Businesses in The Republic of Korea. International Migration, Vol. 52, No. 2, 122-139.

Governo de Portugal (2015). Plano Estratégico para as Migrações 2015-2020. Disponível em https://ec.europa.eu/migrant-integration/country/portugal. Acedido em 01.06.2017 
Hatzigeorgiou, A. (2010). The contribution of migrants in enhancing foreign trade. In OECD (Ed.), Open for Business: Migrant Entrepreneurship in OECD Countries, pp. 273-279. OECD Publishing.

Hout, M., \& Rosen, H. (2000). Self-Employment, Family Background, and Race. The Journal of Human Resources, Vol. 35, No. 4, 670-692.

INE (2003a). Imigrante Permanente. Disponível em http://smi.ine.pt/Conceito/Detalhes/5746. Acedido em 13.11.2016

INE (2003b). Imigrante Temporário. Disponível em http://smi.ine.pt/Conceito/Detalhes/5309. Acedido em 13.11.2016

Kloosterman, R., \& Rath, J. (2010). Shifting landscapes of immigrant entrepreneurship. In OECD (Ed.), Open for Business: Migrant Entrepreneurship in OECD Countries, pp. 101-123. OECD Publishing.

Lassmann, A., \& Busch, C. (2015). Revisiting native and immigrant entrepreneurial activity. Small Business Economics, Vol. 45, No. 4, 841-873.

Mason, J. (2002). Qualitative Researching. London: Sage Publications.

Mestres, J. (2010). Migrant entrepreneurship in OECD countries and its contribution to employment. In OECD (Ed.), Open for Business: Migrant Entrepreneurship in OECD Countries, pp. 23-62. OECD Publishing.

Malheiros, J., \& Padilha, B. (2010). Mulheres Emigrantes Empreendedoras. Lisboa: Comissão para a Cidadania e Igualdade de Género.

OECD (2010). Entrepreneurship and Migrants. OECD Working Party on SMEs and Entrepreneurship. OECD.

Oliveira, C. R. (2005). Empresários de Origem Imigrante, Estratégias de Inserção Económica em Portugal. Lisboa: ACIME 2.

Oliveira, C. R. (2008). Determinantes das estratégias empresariais de imigrantes em Portugal. Revista Migrações, No. 3, 109-138.

Oliveira, C. R. (2010). The determinants of immigrant entrepreneurship and employment creation in Portugal. In OECD (Ed.), Open for Business: Migrant Entrepreneurship in OECD Countries, pp. 125-148. OECD Publishing.

Peixoto, J. (2008). Limites e oportunidades do empreendedorismo imigrante. Revista Migrações, No. 3, 305-307.

Perruchoud, R., \& Redpath-Cross, J. (2011). International Migration Law: Glossary on Migration (2 $\mathrm{a}$ ed.). Geneva: International Organization for Migration.

Ramos, M. C. P. (2007). Imigração, Desenvolvimento e Competitividade em Portugal. Revista Economia e Sociologia, No. 84, 20 semestre, 71-108. 
Ramos, M. C. P. (2013a). Globalização e Multiculturalismo. Revista Eletrónica Inter-Legere, No. $13,75-101$.

Ramos, M. C. P. (2013b). Mobilidades qualificadas e empreendedoras no contexto dos movimentos migratórios contemporâneos e da crise económica. Ambivalências, Vol. 1, No. 2, 73-103.

Ramos, M. C. P. \& Ramos, M. N. P. (2014). Associativismo migrante, participação e inclusão social no espaço urbano. In Anais Eletrônicos do XXII Encontro Estadual de História da ANPUH SP, ed. ANPUH - São Paulo, 1a ed., 1-15.

Rath, J., \& Swagerman, A. (2016). Promoting Ethnic Entrepreneurship in European Cities: Sometimes Ambitious, Mostly Absent, Rarely Addressing Structural Features. International Migration, Vol. 54, No. 1, 152-166.

Sasse, G., \& Thielemann, E. (2005). A Research Agenda for the Study of Migrants and Minorities in Europe. Journal Compilation, Vol. 43, 655-671.

Takenaka, A., \& Paerregaard, K. (2015). How Contexts of Reception Matter: Comparing Peruvian Migrants' Economic Trajectories in Japan and the US. International Migration, Vol. 53, No. 2, 236-249.

Tedesco, C. J. (2017). Ser imigrante e empreendedor: lógicas e sentidos. Aspectos da imigração brasileira na Itália. Revista de Ciências Sociais - Mediações, Vol.22, No.1, 213-242.

Tubergen, F. V. (2005). Self-Employment of Immigrants: A Cross-National Study of 17 Western Societies. Social Forces, Vol. 84, No. 2, 709-732.

Vinogradov, E. (2011). Ethical Aspects of Research on Ethnic/Immigrant Entrepreneurship. Entrepreneurship Research Journal, Vol. 1, No. 3, 1-25.

Wang, Q., \& Morrell, E. (2015). Gender and entrepreneurship revisited from a community perspective: experiences in a new immigrant gateway and beyond. Environment and Planning A, Vol. 47, No. 12, 2645-2662. 